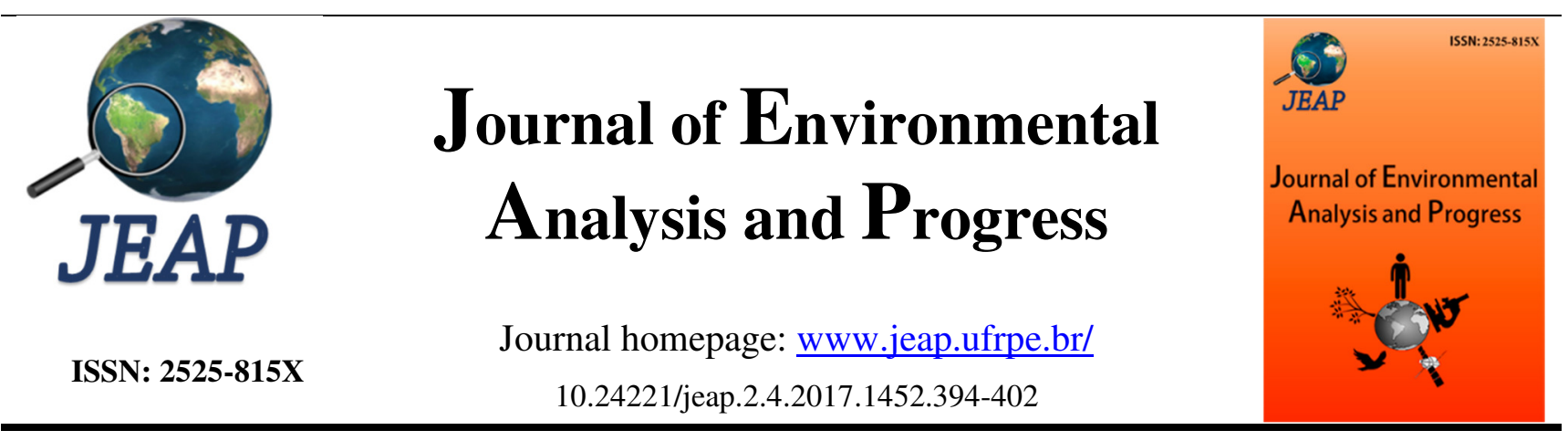

\title{
Variabilidade climática no Agreste de Pernambuco e os desastres decorrentes dos extremos climáticos
}

\section{Climate variability in Agreste of Pernambuco and disasters arising out of climate extremes}

\author{
Maria Luana Torres Pereira ${ }^{\mathrm{a}}$, Maendra Pollinne Arcoverde Soares ${ }^{\mathrm{a}}$, Emanuel Araújo Silva ${ }^{\mathrm{a}}$, \\ Abelardo Antônio de Assunção Montenegro ${ }^{a}$, Werônica Meira de Souza ${ }^{a}$ \\ a Universidade Federal Rural de Pernambuco-UFRPE, Unidade Acadêmica de Garanhuns-UAG. Avenida Bom Pastor, \\ s/n, Boa Vista, Garanhuns, Pernambuco, Brasil. CEP: 55292-270. E-mail: luan-atorres@hotmail.com; \\ maendra.arcoverde@gmail.com; $\quad$ emanuel.ufrpe@gmail.com;
} weronicameira@gmail.com. Autor correspondente.

\section{A R T I C L E I N F O}

Recebido 29 Jun 2017

Aceito 10 Jul 2017

Publicado 15 Ago 2017

\begin{abstract}
A B S T R A C T
Climate change is a reality for the world's population and the evidence are part of our daily lives, with threats to the infrastructure of cities, decreased productivity in crops, changes in rivers and oceans. The objective of this study is to classify weather patterns in Agreste through Rain Anomaly Index (RAI), to characterize the severity of dry and moist years and analyze the disasters arising from climate variability. We selected 14 rain gauge stations distributed in the Agreste from 1963 to 2013. The annual RAI and the wet period were calculated. The survey of official data of disasters associated with extreme weather (dry and floods) of the 14 cities studied was conducted in 1963 to 2013, through the Integrated Information System of the Ministry of Integration of Disaster. The results indicated that the wet period corresponds to the months from February to July and the dry period from August to January. Through the RAI was diagnosed a change in the pattern of precipitation, showing that by the end of the 80 s there is a higher frequency of wet years and that from the 90s there was a significant decrease in these years, i.e., the years dry now predominate in the region. In the drier classified official documents were issued decreeing state public and emergency disaster, caused by the drought and/or drought, with social impacts and huge losses in agriculture and livestock, in addition to human and pet supplies.
\end{abstract}

Keywords: Rainfall, drought, climate trend.

\section{R E S U M O}

As mudanças climáticas são uma realidade para a população mundial e as evidências fazem parte do dia a dia, com ameaças à infraestrutura das cidades, diminuição da produtividade nas lavouras, alterações nos rios e oceanos. O objetivo deste estudo é classificar padrões climáticos na região central do Agreste de Pernambuco através do Índice de Anomalia de Chuva (IAC), visando caracterizar a severidade dos anos secos e chuvosos e analisar os desastres decorrentes das variabilidades climáticas. Foram selecionadas 14 estações pluviométricas distribuídas no Agreste Central no período de 1963 a 2013. Calculou-se o IAC anual e do período úmido. Foi realizado o levantamento dos dados oficiais dos desastres associados aos extremos climáticos (secas e enchentes) dos 14 municípios estudados no período de 1963 a 2013, através do Sistema Integrado de Informações sobre Desastres (S2ID) do Ministério da Integração. Os resultados indicaram que o período úmido corresponde aos meses de fevereiro a julho, sendo o período seco de 
agosto a janeiro. Através do IAC diagnosticou-se uma mudança no padrão da precipitação, evidenciando que até o final da década de 80 havia uma frequência maior dos anos úmidos, e que a partir da década de 90 houve uma diminuição significativa desses anos, ou seja, os anos secos passaram a predominar na região. Nos anos classificados como mais secos, foram emitidos documentos oficiais decretando estado de calamidade pública e/ou emergência, ocasionado pela seca e/ou estiagem, com impactos sociais e grandes prejuízos à agricultura e pecuária, todavia, também comprometendo o abastecimento humano e animal.

Palavras-Chave: Precipitação pluviométrica, seca, tendência climática.

\section{Introdução}

Os efeitos das variabilidades climáticas e possivelmente das mudanças climáticas vêm afetando todo o planeta com desastres em grande escala, com alterações nos recursos hídricos e na agricultura no decorrer dos anos. Assis, Souza \& Sobral (2015) afirmam que as mudanças do clima têm intensificado cada vez mais a problemática da escassez hídrica, sobretudo em áreas áridas e semiáridas do planeta, destacando o semiárido do Nordeste do Brasil, uma vez que apresenta uma grande tendência à aridização, acompanhada de diminuição da oferta hídrica em função da alteração nos padrões pluviométricos, com diminuição da frequência e intensidade das chuvas.

O semiárido nordestino apresenta grande variabilidade espacial e temporal das chuvas, com precipitações irregulares concentradas em poucos meses. Essa região também é caracterizada com alto potencial para evaporação da água, em função da grande disponibilidade de energia solar, das temperaturas elevadas e da baixa umidade do ar (Assis, Souza \& Sobral, 2015).

Araújo, Moraes Neto \& Sousa (2009) afirmam que, devido à irregularidade da precipitação, é necessário realizar um monitoramento através de índices climáticos, uma vez que, através deles, pode-se desenvolver um sistema de acompanhamento das características dos períodos de seca ou chuvosos, com informações anuais ou mensais, com as quais se pode conhecer a climatologia de uma determinada região e verificar os impactos que o clima causa sobre a distribuição da precipitação pluviométrica.

O Agreste Central é considerado a região do Agreste de Pernambuco com maior urbanização. Possui cidades de importância interregional, como Caruaru e Belo Jardim. Apresenta vários pólos industriais, sobretudo no setor alimentício, além de atividades agrícolas diversificadas e criação de gado (PE-AZ, 2016). Dessa forma, o objetivo desse estudo é classificar padrões climáticos no Agreste Central pernambucano, através do Índice de Anomalia de Chuva (IAC), visando caracterizar a severidade dos anos secos e chuvosos e os desastres decorrentes dos extremos climáticos, tendo em vista a importância desta região no cenário Estadual e Nacional.

\section{Material e Métodos}

\section{Localização da área de estudo}

A região Agreste de Pernambuco é subdividida em três Regiões de Desenvolvimento (RD's): Agreste Central, Agreste Meridional e Agreste Setentrional, sendo estas regiões compostas por: 26,26 e 19 municípios, respectivamente, totalizando 71 municípios (Figura 1).

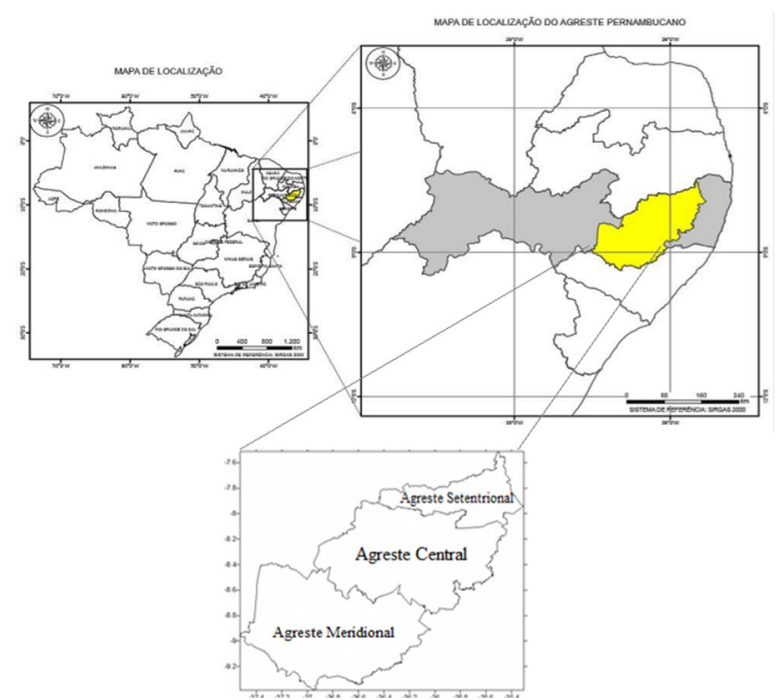

Figura 1. Mapa de localização do Brasil, com identificação do estado de Pernambuco e destaque para as regiões do Agreste Setentrional, Central e Meridional. Fonte: ITEP (2017), modificado pelos autores.

O Agreste Central, região do presente estudo, é composto pelos seguintes municípios: Agrestina, Alagoinha, Altinho, Barra de Guabiraba, Belo Jardim, Bezerros, Bonito, Brejo da Madre de Deus, Cachoeirinha, Camocim de São Felix, Caruaru, Cupira, Gravatá, Ibirajuba, Jatáuba, Lagoa dos Gatos, Panelas, Pesqueira, Poção, Riacho das Almas, Sairé, Sanharó, São Bento do Una, São Caitano, São Joaquim do Monte e Tacaimbó.

\section{Dados}

Foi realizado o levantamento dos dados mensais de precipitação pluviométrica existentes 
no período de 1962 a 2013, dos 26 municípios que compreendem a região do Agreste Central de Pernambuco. Após a análise dos dados foram selecionados apenas 14 postos pluviométricos, com séries climatológicas que constituíssem um período de dados maior ou igual a 30 anos. Esses dados das estações pluviométricas foram fornecidos gratuitamente pela Agência Pernambucana de Águas e Clima (APAC) e pelo Instituto Nacional de Meteorologia (INMET). A distribuição espacial das estações pluviométricas utilizadas neste estudo está representada na Figura 2.

Figura 2. Distribuição espacial das estações pluviométricas no Agreste Central de Pernambuco. Fonte: Autores (2017).

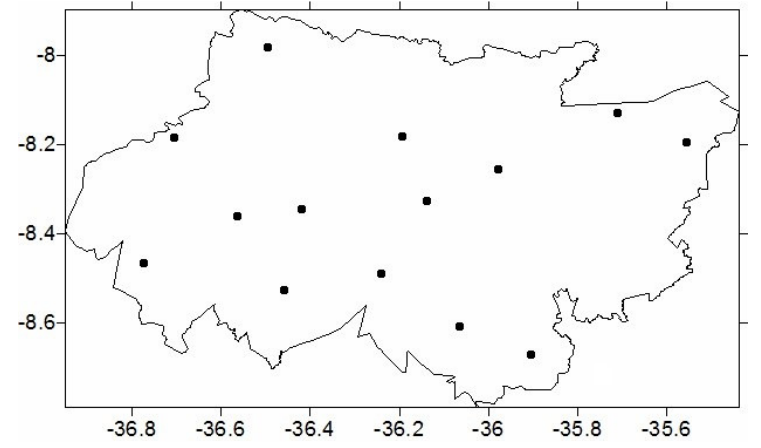

Clarke \& Silva (2004) sugeriram que as séries de dados têm que ser suficientemente longas e representativas do local de estudo, pois só assim pode-se observar a variabilidade do comportamento climático de uma região, principalmente em relação às chuvas intensas e secas prolongadas.

Também foi realizado o levantamento dos desastres (secas, estiagem, inundações) decorrentes dos extremos climáticos, dos 14 municípios analisados no período de 1962 a 2013, por meio de Decretos, Portarias (atos administrativos) e Avadan (avaliação de danos), fornecidos pelo Sistema Integrado de Informações sobre Desastres (S2ID) do Ministério da Integração Nacional.

De acordo com o Ministério da Integração Nacional (2003), a estiagem resulta da diminuição das precipitações pluviométricas, do atraso ou da ausência de chuvas para o período chuvoso de um determinado município. A seca é uma estiagem prolongada, caracterizada por provocar uma redução das reservas hídricas existentes. As estiagens quando comparadas às secas, caracterizam-se por sua menor intensidade e por ocorrerem durante períodos de tempo menores.

\section{Procedimentos metodológicos}

Primeiramente, foi realizada uma análise de consistência das séries temporais, através da análise da qualidade dos dados pluviométricos brutos, verificação da homogeneidade da série em relação ao padrão regional.

Em seguida, uma atualização da climatologia mensal da precipitação pluviométrica do Agreste Central para o período de 1963 a 2013, e da média aritmética para identificação do período chuvoso da região. Posteriormente, aplicou-se o Índice de Anomalia de Chuva (IAC), onde foi obtida a severidade dos anos secos e úmidos da região estudada. O IAC é uma metodologia que vem sendo aplicada e difundida no Nordeste do Brasil para caracterizar os períodos extremos (secos e chuvosos), assim como as diferentes intensidades desses eventos no tempo e no espaço. Um ponto crucial no emprego de um índice como esse, assim como de qualquer outro índice climático, reside na escolha do patamar a ser estabelecido para a definição de um período de seca. Nesse sentido, Freitas (2004, 2005), observou que, com base no mesmo, é possível fazer uma comparação das condições atuais de precipitação em relação aos valores históricos, servindo ainda para avaliar a distribuição espacial do evento, consoante sua intensidade.

O Índice de Anomalia de Chuva-IAC (Rainfall Anomaly Index-RAI), que analisa a frequência em que ocorrem os anos secos e chuvosos, além da intensidade do evento. O IAC foi desenvolvido por Van Rooy (1965), adaptado por Freitas (2004) e Araújo (2007), para a Região Nordeste, possibilitando classificar o ano como sendo: seco, normal ou chuvoso. A avaliação do grau de severidade e duração dos períodos secos e úmidos foi realizada através do cálculo do índice IAC (Freitas, 2004; 2005), obtido a partir das Equações 1 e 2:

para anomalias postivas:

$\mathrm{IAC}=3\left[\frac{(\mathrm{N}-\overline{\mathrm{N}})}{(\mathrm{M}-\overline{\mathrm{N}})}\right]$

para anomalias negativas:

$\mathrm{IAC}=-3\left[\frac{(\mathrm{N}-\overline{\mathrm{N}})}{(\overline{\mathrm{X}}-\overline{\mathrm{N}})}\right]$

onde: $N$ : precipitação anual $(\mathrm{mm}) ; \quad \bar{N}$ : precipitação média anual da série histórica $(\mathrm{mm})$; $M$ : média das 10 maiores precipitações anuais da série histórica $(\mathrm{mm}) ; \bar{X}$ : média das 10 menores precipitações anuais da série histórica $(\mathrm{mm})$. 
Logo, assumindo-se que as anomalias positivas representam valores acima da média histórica de precipitação e que, as anomalias negativas são os valores abaixo desta média histórica. Adotou-se a partir da metodologia proposta por Freitas $(2004,2005)$ e Araújo (2007), a classificação de anos secos e úmidos como um indicador climático para a intensidade destas anomalias, conforme Tabela 1.

Tabela 1. Classes de intensidade do índice de anomalia de chuva.

\begin{tabular}{cc}
\hline Faixa do IAC & Classe de intensidade \\
\hline Acima de 4 & Extremamente úmido \\
2 a 4 & Muito úmido \\
0 a 2 & Úmido \\
0 a -2 & Seco \\
-2 a -4 & Muito seco \\
\hline
\end{tabular}

Fonte: Adaptado por Araújo, Moraes Neto \& Sousa (2009).

\section{Resultados}

A climatologia total anual da precipitação pluviométrica atualizada para o período de 1963 a 2013 (50 anos), referente aos postos pluviométricos que compreendem o Agreste Central de Pernambuco, foi de 648,61 mm. Na série histórica selecionada foi possível identificar o período úmido (fevereiro a julho), com um total acumulado de 469,34 $\mathrm{mm}$ e o período seco (agosto a janeiro), com um total de precipitação de $179,28 \mathrm{~mm}$.

Destacaram-se os meses de março, abril e junho, representando os meses mais chuvosos da região, e o trimestre: setembro, outubro e novembro, como o mais seco (Figura 3).

Figura 3. Climatologia da precipitação pluviométrica mensal do Agreste Central de Pernambuco, com destaque para o período chuvoso no período de 1963 a 2013.

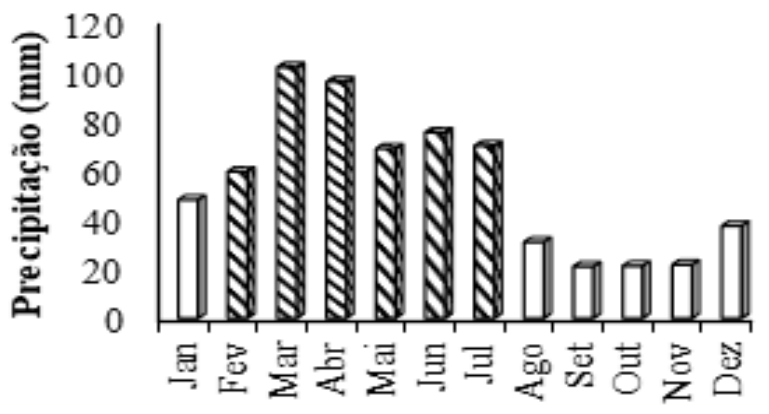

Esses fenômenos atuam em sub-regiões distintas e, também, se superpõem em algumas sub-regiões, nas mesmas épocas ou em épocas diferentes. Alguns desses sistemas são influenciados pelo albedo e orografia.
O IAC foi utilizado para avaliar o grau de severidade e duração de períodos secos e úmidos no Vale do Ipojuca, considerou-se o total de chuva anual (Figura 4) e o período úmido de fevereiro a julho (Figura 5). O valor positivo de IAC significa que um determinado ano foi chuvoso, e que dependendo do seu valor, este atinge a classe de chuvoso, muito chuvoso ou extremamente chuvoso. Similarmente aos valores positivos de IAC, os valores negativos representam os anos secos no Agreste Central, com classificação de severidade de seco, muito seco ou extremamente seco.

No Agreste Central, o IAC apresenta grande variabilidade (Figura 4), com uma frequência similar de valores positivos e negativos até o final da década de 80 (1989). No entanto, do início da década de 90 até 2013, ocorre uma modificação na precipitação, com uma maior frequência de anos mais secos, evidenciando uma possível variação climática da precipitação anual e principalmente no período úmido (Figura 5), destacando-se que os anos secos estão mais evidentes na região.

Figura 4. Índice de Anomalia de Chuva anual no Agreste Central de Pernambuco

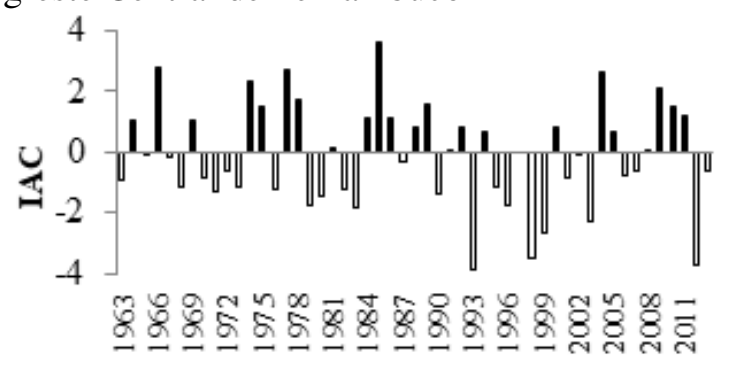

Figura 5. Índice de Anomalia de Chuva do semestre chuvoso no Agreste Central de Pernambuco.

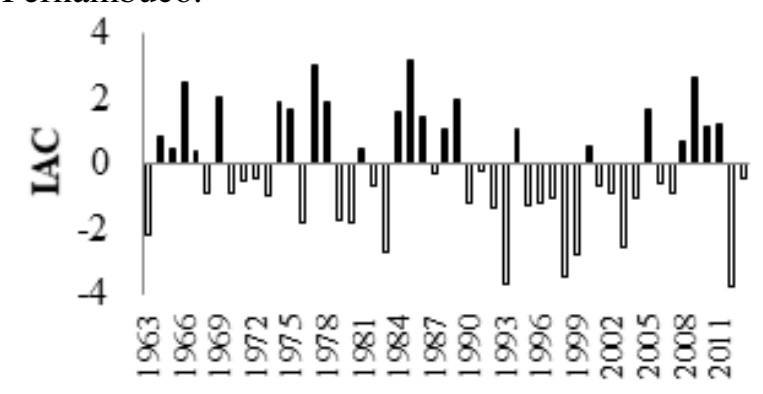

Após a análise dos extremos climáticos (secos e úmido) obtidos através do IAC, identificaram-se os documentos emitidos oficialmente através dos registros disponíveis no Ministério da Integração Nacional, os desastres ocorridos nos três anos mais secos $(1993,1998$ e 2012) e nos anos mais úmidos $(1966,1977$ e 1985), nos municípios estudados, conforme a Tabela 2. Ressalta-se que, apenas em 
Cachoeirinha, não foi encontrado nenhum documento oficial em toda a série de dados.

Em 1993 foram emitidas 14 portarias decretando estado de calamidade pública, ocasionada pela seca, e uma pela estiagem, associadas aos baixos índices pluviométricos registrados na região. Destaca-se Alagoinha com duas portarias em 1993, ocasionadas pela seca e estiagem.

Identificaram-se 11 documentos oficiais em 1998 decretando estado de emergência ocasionado pela estiagem, com exceção dos municípios de Alagoinha e Riacho das Almas. Em 2012 foram 15 registros, seis através de Portarias e nove em Avadan, devido à estiagem prologada em decorrência dos baixos índices pluviométricos. Em Poção e Riacho das Almas foram emitidos dois documentos oficiais em 2012.

Os maiores impactos foram registrados na área rural, com grandes prejuízos à agricultura, com perdas na produção de grãos, cereais, leguminosas, fruticulturas e horticulturas, na pecuária houve perdas de grande e pequeno porte, e baixa produtividade de leite, além dos prejuízos sociais.

Com relação aos anos mais úmidos, verificou-se apenas um registro oficial em Caruaru no ano de 1985, ocasionado pelas inundações, devido às chuvas acima da média histórica.

Tabela 2. Relação dos municípios com identificação das datas, dos documentos oficiais e dos desastres no Agreste Central de Pernambuco. Fonte: Autores (2017).

\begin{tabular}{|c|c|c|c|}
\hline Município & Data do evento & Documento & Evento \\
\hline \multirow{3}{*}{ Alagoinha } & 29/03/1993 & Portaria & Estiagem \\
\hline & 08/08/1993 & Portaria & Seca \\
\hline & $17 / 04 / 2012$ & Avadan & Estiagem \\
\hline \multirow{3}{*}{ Belo Jardim } & $28 / 04 / 1993$ & Portaria & Seca \\
\hline & 26/05/1998 & Decreto & Estiagem \\
\hline & $15 / 05 / 2012$ & Avadan & Estiagem \\
\hline \multirow{3}{*}{ Bezerros } & $28 / 04 / 1993$ & Portaria & Seca \\
\hline & 26/05/1998 & Decreto & Estiagem \\
\hline & $07 / 05 / 2012$ & Avadan & Estiagem \\
\hline \multirow{3}{*}{ Brejo da Madre de Deus } & $08 / 08 / 1993$ & Portaria & Seca \\
\hline & $26 / 02 / 1998$ & Portaria & Estiagem \\
\hline & $04 / 05 / 2012$ & Avadan & Estiagem \\
\hline \multirow{3}{*}{ Caruaru } & $18 / 04 / 1985$ & Jornal & Inundações \\
\hline & 08/08/1993 & Portaria & Seca \\
\hline & $24 / 04 / 2012$ & Portaria & Estiagem \\
\hline \multirow{2}{*}{ Gravatá } & $17 / 06 / 1993$ & Portaria & Seca \\
\hline & $26 / 05 / 1998$ & Decreto & Estiagem \\
\hline \multirow{3}{*}{ Jataúba } & $16 / 03 / 1993$ & Portaria & Seca \\
\hline & 26/05/1998 & Decreto & Estiagem \\
\hline & 27/04/2012 & Avadan & Estiagem \\
\hline \multirow{4}{*}{ Poção } & $08 / 08 / 1993$ & Portaria & Seca \\
\hline & 26/05/1998 & Decreto & Estiagem \\
\hline & $01 / 03 / 2012$ & Avadan & Estiagem \\
\hline & $23 / 08 / 2012$ & Portaria & Estiagem \\
\hline \multirow{3}{*}{ Pesqueira } & $08 / 08 / 1993$ & Portaria & Seca \\
\hline & 26/05/1998 & Decreto & Estiagem \\
\hline & $07 / 04 / 2012$ & Portaria & Estiagem \\
\hline \multirow{3}{*}{ Riacho das Almas } & $13 / 04 / 1993$ & Portaria & Seca \\
\hline & 04/05/2012 & Portaria & Estiagem \\
\hline & $01 / 11 / 2012$ & Portaria & Estiagem \\
\hline \multirow{3}{*}{ Sanharó } & 09/06/1993 & Portaria & Seca \\
\hline & 26/05/1998 & Decreto & Estiagem \\
\hline & $23 / 04 / 2012$ & Avadan & Estiagem \\
\hline \multirow{3}{*}{ São Bento do Una } & $08 / 08 / 1993$ & Portaria & Seca \\
\hline & 26/05/1998 & Decreto & Estiagem \\
\hline & $14 / 05 / 2012$ & Avadan & Estiagem \\
\hline
\end{tabular}


Journal of Environmental Analysis and Progress V. 02 N. 04 (2017) 394-402

\begin{tabular}{llll}
\multirow{3}{*}{ São Caetano } & $18 / 05 / 1993$ & Portaria & Seca \\
& $21 / 01 / 1998$ & Portaria & Estiagem \\
& $04 / 05 / 2012$ & Avadan & Estiagem \\
\hline \multirow{2}{*}{ Tacaimbó } & $12 / 04 / 1993$ & Portaria & Seca \\
& $26 / 05 / 1998$ & Decreto & Estiagem \\
& $23 / 04 / 2012$ & Portaria & Estiagem \\
\hline
\end{tabular}

A partir da análise da variabilidade temporal anual do IAC no Agreste Central 1, identificou-se que os anos 1966, 1977 e 1985 apresentaram os maiores índices positivos, todos classificados como muito úmidos, sendo 1993, 1998 e 2012 os anos com os maiores índices negativos, considerados os mais secos. Desta forma, para analisar a variabilidade espacial e a intensidade do IAC nesses anos extremos (chuvosos e secos), foi realizada a espacialização para os anos úmidos (Figura 6) e secos (Figura 7), de acordo com a intensidade do IAC.

Nos anos de 1966 e 1977 houve predominância das classificações úmido e muito úmido para o setor norte e oeste central, respectivamente, e em praticamente toda a região do Vale do Ipojuca em 1985 (Figura 6). Ressaltase que o ano de 1985 foi considerado o mais chuvoso de toda a série, e o único ano com registro oficial de inundações.
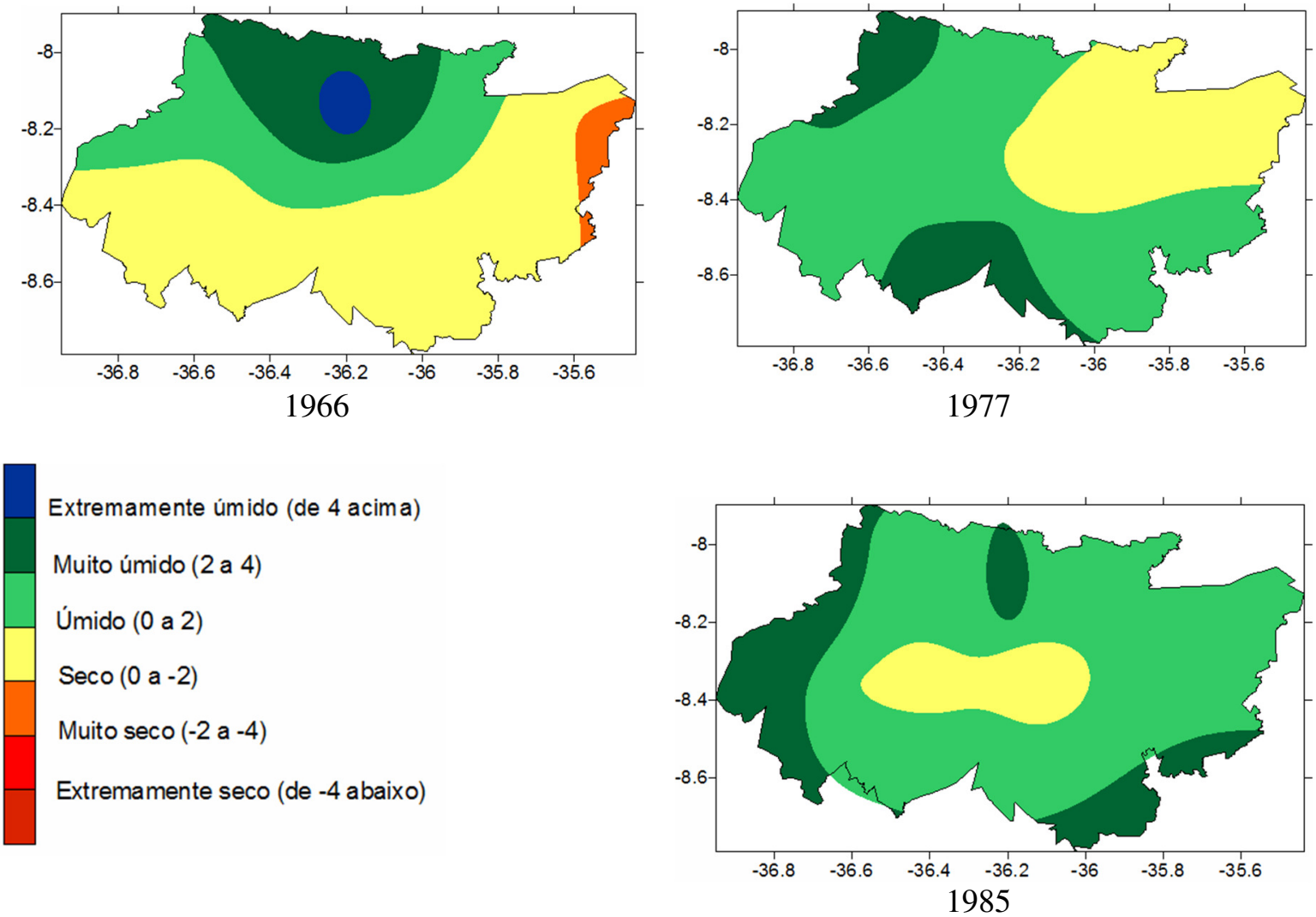

Figura 6. Índice de Anomalia de chuva (IAC) para os anos muito úmidos: 1966, 1977, 1985 no Agreste Central de Pernambuco.

A Figura 7 mostra os anos de 1993, 1998 e 2012 que obtiveram a maior quantidade de IAC negativos para o Vale do Ipojuca. O El Niño com forte intensidade que atuou no período de 1998, foi o principal responsável pela redução considerável da precipitação neste ano. Segundo Assis et al. (2012), evidencia-se que um dos motivos para a classificação desses anos, na bacia hidrográfica do Rio Pajeú, serem considerados secos foi devido à ocorrência do El Niño. 

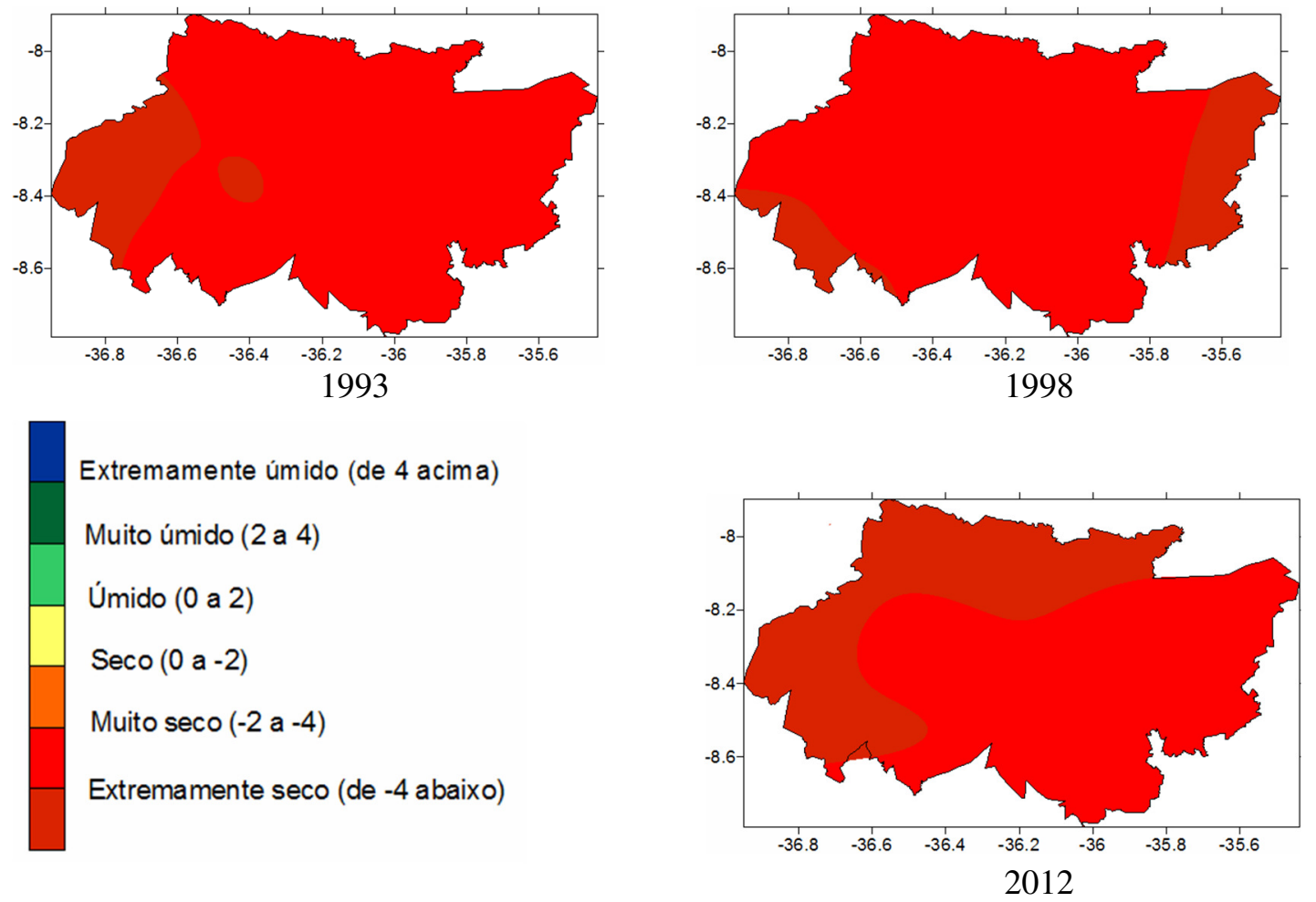

Figura 7. Índice de anomalia de chuva nos anos muito secos: 1993, 1998 e 20121985 no Agreste Central de Pernambuco.

\section{Discussão}

Os principais sistemas meteorológicos responsáveis pelas chuvas nessa região são: Zona de Convergência Intertropical (ZCIT), Vórtices Ciclônicos de Ar Superior-VCAS, as instabilidades associadas às Frentes Frias e os Distúrbios de Leste (Lacerda, Ferreira \& Souza, 2006).

A análise do comportamento das chuvas se torna importante uma vez que, possibilita detectar tendências ou alterações no clima, em escalas locais, regionais, estaduais, nacionais e continentais (Marcuzzo, Goularte \& Melo, 2012). O cálculo do IAC pode ser utilizado como uma ferramenta para auxiliar o acompanhamento climático e a variabilidade pluviométrica de uma determinada área, podendo auxiliar no gerenciamento agrícola e nos recursos hídricos e, então empreender ações de adaptação e mitigação.

Apesar das incertezas em relação às mudanças climáticas, as variabilidades do clima ainda representam obstáculos para o planejamento das cidades. Apesar deste fato, ações devem ser tomadas para evitar ou minimizar os impactos decorrentes das possíveis mudanças no clima e das variabilidades climáticas, pois exercem uma influência significativa sobre as atividades humanas que podem oscilar quanto à temperatura, precipitação e frequência de eventos extremos como: secas e chuvas intensas, resultando em impactos na agricultura, nos recursos hídricos, na saúde, sobre o meio ambiente, em escala local ou regional (Souza \& Azevedo, 2012).

A escolha do patamar para a separação entre anos secos e úmidos, não deve ser, portanto, arbitrária, mas deve ser escolhido com base no conhecimento climático da região, analisando as características dos períodos históricos de secas e das correspondentes consequências à população e ao meio ambiente atingido. Esses efeitos dependem, por sua vez, da infraestrutura hídrica existente, isto é, variam com o tempo (Da Silva, 2009).

\section{Conclusão}

O semestre mais chuvoso no Agreste Central correspondeu ao período de fevereiro a julho, com destaque para os meses de março e abril, que apresentaram os maiores valores, e os meses mais secos de setembro a novembro.

A partir da década de 1990, identificou-se diminuição da frequência dos anos Muito Úmidos, e aumento dos anos Muito Secos em relação aos anos chuvosos, apresentando uma modificação no padrão da precipitação, ou seja, os anos secos passaram a predominar na região.

Os anos que apresentaram maior destaque nesta análise foram: 1966, 1977, 1985, onde foram encontrados os maiores valores de precipitação pluviométrica anual, classificados como muito úmidos; os anos de 1993, 1998 e 2012 foram classificados como muito secos. 
Nos anos mais secos foram emitidos documentos oficiais decretando estado de calamidade pública e/ou emergência, ocasionado pela seca e/ou estiagem, com impactos sociais e grandes prejuízos na agricultura e pecuária, além do abastecimento humano e animal.

Os impactos sociais ocasionados pela estiagem e seca, em um determinado ano, nem sempre está relacionado à falta de chuvas de um determinado ano, mas pela distribuição e frequência da precipitação pluviométrica antes do ano de seca em análise, pois anos de chuvas irregulares antes de um ano classificado seco, não tão severo, pode ocasionar um profundo caos social bem mais abrangente do que um ano de seca mais severa ocorrido após alguns anos com chuvas mais regulares.

O cálculo do IAC pode ser utilizado como uma ferramenta para auxiliar o acompanhamento climático e a variabilidade pluviométrica de uma determinada área, podendo auxiliar no gerenciamento agrícola e nos recursos hídricos e, então empreender ações de adaptação e mitigação dos desastres decorrentes dos extremos climáticos.

\section{Agradecimentos}

Ao Programa Institucional de Bolsas de Iniciação Científica PIBIC/CNPq/UFRPE pela concessão de bolsa para desenvolvimento da pesquisa. À Fundação de Amparo a Ciência e Tecnologia de Pernambuco (FACEPE) por meio do Projeto de Pesquisa APQ-0762-1.07/15 ao Ministério da Ciência, Tecnologia e Inovação (MCTI), por intermédio do Conselho Nacional de Desenvolvimento Científico e Tecnológico (CNPq), e a Agência Nacional de Águas (ANA), por meio do edital MCTI/CNPq/ANA n.23/2015.

\section{Referências}

ANDRADE, M. C. 2009. Geografia de Pernambuco: Ambiente e sociedade. João PessoaPB. Editora Grafset. 35p.

ARAUJO, L. E.; MORAES NETO, J. M.; SOUSA, F. A. S. 2013. Análise Climática da Bacia do rio Paraíba - índice de Anomalia de Chuva (IAC). Revista de Engenharia Ambiental, v. 6, n. 3 , p. 508-523.

ASSIS, J. M. O.; SOBRAL, M. C. M.; SOUZA, W. M. 2014. Análise de Detecção de Variabilidades Climáticas com Base na Precipitação nas Bacias Hidrográficas do Sertão de Pernambuco. Revista Brasileira de Geografia Física, v. 3, p. 630-645.
ASSIS, J. M. O.; SOUZA, W. M.; SOBRAL, M. C. M. 2015. Climate analysis of the rainfall in the lower-middle stretch of the São Francisco river basin based on the rain anomaly index. Revista Brasileira de Ciências Ambientais, v. 2, p. 188202.

BRITTO, F.; BARLETTA, R.; MENDONÇA, M. 2006. Regionalização Sazonal e Mensal da Precipitação Pluvial Máxima no Estado do Rio Grande do Sul. Revista Brasileira de Climatologia, v. 2, n. 2, p. 35-51.

ClARKE, R. T.; SILVA, B. C. 2004. Análise estatística de chuvas intensas na bacia do rio São Francisco. Revista Brasileira de Meteorologia, v. 19, n. 3, p. 265-272.

CONDEPE/FIDEM. Agência Estadual de Planejamento e Pesquisas de Pernambuco. 2011. Pernambuco em Mapas. Recife.

DA SILVA, D. F. 2009. Análise de aspectos climatológicos, agroeconômicos, ambientais e de seus efeitos sobre a bacia hidrográfica do rio Mundaú (AL e PE). Tese (Doutorado em Recursos Naturais), Universidade Federal de Campina Grande, Campina Grande.

FILHO, C. A. S. G. 2012. Território Rural do Agreste Meridional, do Sertão do Pajeú e da Mata Sul em Pernambuco: acompanhamento e avaliação dos resultados do Programa Desenvolvimento Rural Sustentável de Territórios Rurais.

FREITAS, M. A. S. 2004. A Previsão de Secas e a Gestão Hidroenergética: O Caso da Bacia do Rio Parnaíba no Nordeste do Brasil. In: Seminário Internacional sobre Represas y Operación de Embalses, 2004, Puerto Iguazú. In: Anais do Seminário Internacional sobre Represas y Operación de Embalses. Puerto Iguazú: CACIER, v. 1, p. 1.

FREITAS, M. A. S. 2005. Um Sistema de Suporte à Decisão para o Monitoramento de Secas Meteorológicas em Regiões SemiÁridas. Revista Tecnologia, p. 84-95.

IBGE. Censo Demográfico 2010. Disponível em: www.ibge.gov.br/home/estatistica/populacao/cens o2010. Acesso em: 15/01/2011.

LACERDA, F.; FERREIRA, M. A. F.; SOUZA, W.M. 2006. Climas do Estado de Pernambuco In: Bacias Hidrográficas de Pernambuco. Recife: Comunigraf Editora, pp. 16-17. 
MARCUZZO, F. F. N.; GOULARTE, E. R. P.; MELO, D. C. R. 2010. Mapeamento Espacial, Temporal e Sazonal das Chuvas no Bioma Amazônico do Estado do Tocantins. Anais. In: X Simpósio de Recursos Hídricos do Nordeste, 10.

MONTEIRO, A. A.; TAMANINI, R.; SILVA, L. C. C.; MATTOS, M. R.; MAGNANI, D. F.; OVIDIO, D.; NERO, L. A.; BARROS, M. A. F.; PIRES, E. M. F.; PAQUEREAU, B. P. D.; BELOTI, V. 2007. Características da produção leiteira da região Agreste do Estado de Pernambuco, Brasil. Semina: Ciências Agrárias, v. 8, n. 4 , p. $665-674$.

PE-AZ. Categoria: Regiões, Agreste Central. Disponível em: http://www.pe-az.com.br/oestado/regioes/287-agreste-central. Acesso em: 12 de dezembro de 2016.

VAN ROOY, M. P. 1965. A Rainfall Anomaly Index Independent of Time and Space. Notes, v. 14 , p. 1-43.
SANTOS, E.; MATOS, H.; ALVARENGA, J.; SALES, M. C. L. 2012. A Seca no Nordeste no ano de 2012: Relato sobre prática de convivência com o semiárido no distrito de Iguaçu/CanindéCE. Revista Geonorte, Edição Especial 2, v. 1, n. 5, p. 819-830.

SANTOS, S. M. S.; ASSIS, J. M. O.; SOUZA, W. M. 2014. Tendências de mudanças climáticas na bacia do rio Una, Pernambuco-Brasil. Revista Brasileira de Geografia Física, v. 7, n. 2, p. 243257.

SOUZA, W. M.; AZEVEDO, P. V. 2012. Índices de Detecção de Mudanças Climáticas Derivados da Precipitação Pluviométrica e das Temperaturas em Recife-PE. Revista Brasileira de Geografia Física, v. 1, p. 143-159. 